\title{
METODOLOGIA DE INTERVENÇÃO E AVALIAÇÃO HISTÓRICO-CULTURAL EM CRIANÇAS QUE APRESENTAM DIFICULDADES DE APRENDIZAGEM
}

\author{
Fabiana Lohani de Sousa ${ }^{1}$, Irineu Aliprando Tuim Viotto Filho ${ }^{1}$, José Ricardo da Silva ${ }^{1}$ Vinicius dos \\ Santos Oliveira ${ }^{2}$. \\ ${ }^{1}$ Universidade Estadual Paulista - UNESP, ${ }^{2}$ Universidade do Oeste Paulista - UNOESTE, Presidente Prudente, SP. E-mail: \\ fabianalohani@hotmail.com. Agência financiadora: CNPQ
}

\section{RESUMO}

O trabalho objetiva refletir sobre um processo histórico-cultural de intervenção e avaliação ludopedagógico como essencial na escolarização de crianças que apresentam dificuldades de aprendizagem. Este objetivo emerge da constatação de que, na escola, eventualmente, as crianças são avaliadas de forma padronizada e taxativa. A teoria histórico-cultural nos auxilia na crítica de avaliações dessa natureza que não consideram os sujeitos em suas individualidades. Por esta razão, realizamos um processo de intervenção e em uma escola pública de Presidente Prudente/SP, com crianças do terceiro ano (08 anos de idade) que apresentavam queixas relacionadas a dificuldades de aprendizagem e, simultaneamente, através de um processo de intervenção ludo-pedagógico, procuramos avaliar esses sujeitos em atividade e respeitando o seu processo histórico-cultural de desenvolvimento. Nesse sentido, ensejamos discussão relativa à uma metodologia de intervenção e avaliação histórico-cultural de natureza ludo-pedagógica e os resultados apontaram a necessidade de se construir atividades coletivas e que atendam as necessidades das crianças, enfatizando a atividade lúdica em suas vidas e como forma de intervenção e avaliação do seu processo de aprendizagem e desenvolvimento na escola.

Palavras-Chave: avaliação histórico-cultural, atividade ludo-pedagógica, aprendizagem e desenvolvimento.

\section{HISTORICAL-CULTURAL METHODOLOGY OF INTERVENTION AND EVALUATION IN CHILDREN WITH LEARNING DIFFICULTIES}

\begin{abstract}
The present work aims to critique the traditional understandings of teaching and evaluation carried out in the school and to discuss the importance of effecting a historical-cultural and ludopedagogical process of intervention as essential in the schooling of children who present learning difficulties. For that, we carried out an intervention process in a public school in Presidente Prudente/SP with children in the age of 08 years old, who presented complaints of learning difficulties and, at the same time, evaluated the learning process of the same ones, from the Activities carried out with them and respecting their historical-cultural process of development. Finally, we discuss the methodology of intervention that we call ludo-pedagogical in the sense of advancing to the traditional models present in the school. The results point out the need to build collective and ludo-pedagogical activities as a form of intervention and evaluation of the learning process and development of these subjects.
\end{abstract}

Keyword: historical-cultural evaluation, ludo-pedagogic activity, learning and development. 


\section{INTRODUÇÃO}

O tema deste artigo emerge de uma pesquisa de iniciação científica realizada no interior da escola e devidamente aprovada pelo comitê de ética da UNESP-Presidente Prudente pelo processo109/2009 e referente aos trabalhos do GEIPEEthc (Grupo de Estudos, Intervenção e Pesquisa em Educação Escolar e Teoria histórico-cultural), coletivo do qual fazemos parte para a realização de nossos estudos, intervenções e pesquisas. Ao longo do processo de intervenção construímos situações de ensino e avaliação de crianças no interior de uma escola pública de Ensino Fundamental de Presidente Prudente/SP. Na efetivação desse processo, as observações na escola possibilitaram identificar o quanto, a maioria das crianças são submetidas a processos de ensino e avaliação tradicionais e conservadores, os quais, na maioria das vezes, contribuem para a estigmatização e discriminação desses sujeitos no interior da escola.

No entanto e considerando a situação de precarização das escolas públicas brasileiras, sabemos que a efetivação de processos diferenciados de ensino e avaliação tornam-se bastante difíceis, sobretudo porque a maioria dos professores, como também outros educadores da escola pública, trabalham no limite de suas possibilidades e enfrentam como podem, as adversidades do cotidiano escolar e apesar disso, esforçam-se na realização do seu trabalho educativo com as crianças na escola.

Sabemos também que essa difícil situação na qual encontra-se a escola pública, compromete a relação dos professores com os alunos, principalmente com aqueles que encontram dificuldades de aprendizagem escolar, os quais, necessariamente, precisariam de um olhar mais atento por parte dos professores. Soma-se a esta situação, modelos de ensino e avaliação tradicionais e conservadores, como temos visto, os quais, na maioria das vezes, complicam ainda mais o processo de aprendizagem e desenvolvimento das crianças na escola.

Defendemos que o processo de ensino e também de avaliação, deveria voltar-se ao atendimento das necessidades das crianças e, nesse sentido, não deveria limitar-se à constatação do imediato, mas sim, lançar-se na direção da construção de novas possibilidades de aprendizagem e considerando a situação social de desenvolvimento desses sujeitos e enfatizando, sobretudo, o papel do professor como mediador e sujeito mais desenvolvido nesse processo.

Nesse movimento histórico-cultural, o processo de ensino deveria ser dinâmico e diversificado para atender as necessidades das crianças, assim como o processo de avaliação deveria ser coerente com a situação de desenvolvimento desses sujeitos, reconhecendo-os na relação dialética ensino-aprendizagem e respeitando seus limites e singularidades.

Para Libâneo (1994) os estudantes encontram-se na vida e devem ser considerados em processo de aprendizagem e desenvolvimento. Na escola, eventualmente, precisam ser avaliados, no entanto, não de forma taxativa, padronizada e estigmatizante, como tem acontecido nos processos tradicionais de ensino e avaliação.

$\mathrm{Na}$ direção da concretização de um processo de ensino e avaliação histórico-cultural, precisamos partir da realidade objetiva da criança e compreendê-las como síntese de muitas determinações sociais e históricas ou seja, partirmos de um amplo espectro de formação humana ao qual a criança está submetida em sociedade e, obviamente, também na escola, sobretudo porque, além de sua família, e no seu interior a que a mesma encontra condições diferenciadas de aprendizagem, desenvolvimento e humanização.

Sensíveis à essa situação presente nas escolas, o trabalho realizado teve como objetivo refletir sobre um processo histórico-cultural de intervenção e avaliação de natureza ludopedagógico, e realizado junto a crianças com dificuldades de aprendizagem de uma sala de aula do 3o. ano do Ensino Fundamental. Este objetivo emergiu da constatação de que na escola, as crianças vivenciam formas padronizadas de ensino e avaliação que, na maioria das vezes, podem levá-las à situações de estigmatização e discriminação, tais como constatamos ao percebermos que as mesmas eram reconhecidas como "crianças-problema" na escola. 
Ao pensarmos no desenvolvimento de uma metodologia de ensino e avaliação, embasados na teoria histórico-cultural, precisamos reconhecer que crianças em idade escolar precisam ser devidamente orientadas pelo professor no seu processo de aprendizagem e, simultaneamente avaliadas na sua forma de ser, pensar e agir na escola. Isso implica enfatizar a importância de processos de ensino e avaliação histórico-culturais na vida escolar das crianças e que sejam relacionados à vida objetiva desses sujeitos, no sentido de lançá-los à esferas do conhecimento científico, artístico e filosófico construído pela humanidade e que possibilite processos de ensino e avaliação inovadores e voltados ao desenvolvimento humano-genérico na escola (DUARTE, 1995).

\section{METODOLOGIA}

No desenvolvimento do processo histórico-cultural e ludo-pedagógico de intervenção na escola, realizamos 16 encontros com as crianças, os quais foram devidamente planejados, executados e registrados em diário de campo pelos membros do GEIPEE-thc, encontros esses que ocorreram durante o ano de 2016. Esclarecemos que, para a análise de dados, escolhemos 08 encontros apenas, aqueles considerados os mais significativos para os sujeitos que vivenciaram o processo de intervenção e que implicaram participação ativa dos mesmos, segundo nossa avaliação.

A cada encontro de intervenção esperava-se que as crianças aprendessem determinados conteúdos relacionados ao seu processo de alfabetização por meio de atividades lúdicas e enfatizando a participação coletiva nesse processo. Algumas das atividades realizadas foram criação de letras e palavras através de massa de modelar, pinturas e desenhos, assim como momentos de leitura e dramatização de histórias da literatura universal, além de pesquisa histórica sobre os personagens, confecção de figurinos e cenário das histórias, dentre outras atividades de natureza lúdica e pedagógica, isso porque realizadas num clima de entretenimento e diversão, sem negligenciar o trabalho educativo e intencional do professor na efetivação do processo de aprendizagem e desenvolvimento dos sujeitos.

Ao final das intervenções à título de avaliação, havia uma roda de conversa, assim como a produção, por parte das crianças, de histórias contadas e escritas sobre a sua participação e vivência na atividade, com o objetivo de identificar os conhecimentos/conteúdos por elas assimilados, assim como o seu processo de expressão oral e escrita no grupo. Ao final do processo de intervenção, criamos uma peça teatral, decorrente da história coletiva vivida e sistematizada pelas crianças, a qual foi apresentada aos demais alunos da escola. Os dados observados e coletados a partir das intervenções serão, a seguir, discutidos com base nos pressupostos da teoria histórico-cultural.

O processo de intervenção e pesquisa pautou-se nos pressupostos do materialismo histórico dialético e considerando a realidade objetiva das crianças como ponto de partida e ponto de chegada do processo. As observações sistemáticas na escola, assim como a vivência nos encontros de intervenção e sua contínua análise e reflexão pelos membros do GEIPEEthc ao longo de todo o processo, engendraram condições de reflexão crítica e intervenção consciente na realidade concreta da escola, no sentido de se construir as transformações necessárias no seu interior, assim como na própria vida escolar das crianças sujeitos do processo (VIOTTO FILHO, 2009; 2012; VIOTTO FILHO \& ANTUNES, 2013).

\section{RESULTADOS}

Considerando o processo de intervenção realizado no interior da escola, cujas observações, intervenções e avaliações, realizadas pelos membros do GEIPEEthc ao longo das atividades ludopedagógicas, foi possível perceber e identificar mudanças paulatinas nos sujeitos participantes, no entanto, vividas dialeticamente, ou seja, a partir de contradições postas pela realidade, assim como pelas relações sociais escolares e, sobretudo, aquelas construídas ao longo do processo. 
Desde os primeiros encontros de intervenção, os sujeitos, na sua maioria, dispuseram-se a participar e, pouco a pouco foram interagindo, aprendendo e se desenvolvendo, assim como compreendendo a si-mesmos, suas relações com os colegas, professores e membros do GEIPEEthc. Podemos dizer que todo o movimento contraditório de desenvolvimento dos sujeitos participantes das intervenções, ocorreu, sobretudo, em decorrência da sua efetiva participação no processo pois, como afirma Leontiev (1978) é na atividade prática social que os seres humanos se desenvolvem e desta forma configurou-se o processo de intervenção ludo-pedagógico realizado na escola.

Ainda segundo Leontiev (1978) torna-se essencial para o processo de humanização a apropriação das objetivações culturais, tanto os materiais quanto simbólicos. Sendo assim, procuramos criar situações específicas para que os sujeitos pudessem se desenvolver, vez que, como afirma Vigotski (2001), as funções psíquicas humanas, para se desenvolverem, avançam de uma condição elementar para uma condição superior, tendo que a linguagem como elemento essencial e imprescindível desse processo.

Se no início do processo os sujeitos agiam de forma individualista e competitiva e muitas vezes, de forma agressiva uns com os outros, ao longo do processo essas ações foram se transformando. Aos poucos as crianças passaram a valorizar o trabalho em grupo, o reconhecimento e o respeito ao outro, a parceria com o colega para a efetivação de novas aprendizagens e, sobretudo, passaram a valorizar o trabalho do professor como orientador principal do processo de aprendizagem e desenvolvimento na escola, papel realizado pelos membros do GEIPEEthc durante o processo de intervenção.

As falas das crianças, enfatizando "agora sim, consegui aprender" ou mesmo, "que gostoso, fazer uma história juntos" ou ainda, "o teatro ficou muito legal" e "quero escrever outra história", dentre outras falas significativas, nos possibilitam pensar o quanto os sujeitos resignificaram a atividade pedagógica da escola e tiveram oportunidades diferenciadas de aprender e se desenvolver. De certa forma, conseguiram dar um sentido diferenciado ao trabalho educativo a eles dirigido pelos membros do GEIPEEthc, fato que, certamente, nos faz pensar sobre o papel da escola e do professor na transformação da maneira de sentir, pensar e agir dos estudantes na escola.

\section{DISCUSSÃO}

Evidenciamos que processos de ensino e avaliação conservadores, apesar de muito presentes nas escola, pouco favorecem a aprendizagem e o desenvolvimento dos estudantes numa direção crítica e consciente. Quanto as avaliações padronizadas, Moyses e Collares et al (2012) afirmam que os instrumentos positivistas de avaliação, apresentam limites e equívocos, sobretudo porque alimentam-se na crença de uma constatação quantitativa que se torna absoluta na compreensão dos sujeitos avaliados. Tais formas de avaliação, normalmente, contribuem para rotular os sujeitos e não avançam na direção de reconhecimento das capacidades humanas.

Não é difícil identificar que os testes padronizados pressupõem um sujeito abstrato, previsível e pré-determinado, que precisa ter um desempenho padrão e conforme àquilo que a sociedade definiu como normal. Assim, desconsidera as características próprias de cada sujeito avaliado e todo o processo histórico de aprendizagem e desenvolvimento. Nesta concepção de avaliação, a compreensão dos seres humanos é limitada.

A ênfase na superação dos processos de ensino e de avaliação conservadores torna-se mais evidente quando nos colocamos ao lado das crianças na escola pois, a partir dos estudos da teoria histórico-cultural (VIGOTSKI, 1995; LEONTIEV, 1978), sabemos que a atividade do brincar torna-se guia e orientadora da aprendizagem e desenvolvimento das crianças, sobretudo na idade préescolar, no entanto, quando trabalhadas de forma consciente e crítica pelo professor, poderão ser trabalhadas como metodologia de ensino e avaliação nos diferentes níveis de ensino, conforme 
procuramos demonstrar no nosso trabalho de intervenção na escola, sobretudo porque, as crianças das séries iniciais do Ensino Fundamental (entre 06 e 08 anos), apesar de tomarem a atividade de estudo como principal na escola, ainda conseguem se identificar e se motivar a partir da atividade do brincar como forma de apropriação de conhecimentos na escola, conforme foi possível constatar no nosso trabalho de intervenção.

A partir desta compreensão, reconhecemos que a situação social de desenvolvimento vivida pelas crianças, sujeitos da nossa pesquisa, indica uma transição da atividade do brincar para a atividade de estudo, a qual, salientamos, deve ser priorizada no Ensino Fundamental, embora a atividade lúdica e pedagógica possa também fazer parte dos processos de ensino e avaliação dos professores, como defendemos.

As crianças sujeitos do processo de intervenção que realizamos na escola, encontravam-se no 3o.ano do Ensino Fundamental, fato que demandou profundas reflexões para o planejamento das atividades relacionadas a uma metodologia ludo-pedagógica e histórico-cultural de ensino e avaliação, sobretudo porque, como sabemos, a atividade de estudo deve ser prioridade nesse nível de ensino, no entanto, ao trabalharmos com crianças com dificuldade de aprendizagem, o resgate da atividade do brincar tornou-se importante estratégia de motivação social dos mesmos para a aprendizagem de conteúdos e conceitos fundamentais para o seu processo de escolarização e na direção da construção de sua individualidade para-si como afirma Duarte (1993).

Defendemos, portanto, a necessidade das crianças aprenderem e se desenvolverem na escola a partir de novas possibilidades que garantam a apropriação dos conhecimentos humanogenéricos essenciais para a construção de sua individualidade (DUARTE, 1995). Nesse processo, defendemos que uma metodologia de intervenção ludo-pedagógica pode contribuir para com esse processo, sobretudo junto à crianças em idade inicial do Ensino Fundamental que encontram dificuldades de aprendizagem.

Torna-se importante esclarecer que a atividade lúdica na escola, ao contrapor-se ao conservadorismo do trabalho educativo tradicional e rígido, evidencia novas possibilidades, sobretudo nas séries iniciais do Ensino Fundamental, pois a situação lúdica, conforme afirmação de Elkonin (1998), permite a transferência de significado de um objeto a outro, engendra situações fictícias, permite a imaginação e a fantasia a partir do real, segundo as orientações de Vigotsky (2009) e, nesse sentido, se devidamente orientada pelo professor com finalidade educativa, cria condições diferenciadas para a aprendizagem na escola.

A perspectiva teórica adotada nos leva a compreender que essas atividades, pensadas e estruturadas numa perspectiva histórico-cultural possibilitarão aprendizagens significativas e, simultaneamente, engendrarão condições de avaliação dos sujeitos. Na realização de atividades ludo-pedagógicas, numa troca significativa de conhecimentos e experiências teórico-práticas, as crianças e jovens se reconhecem, aprendem e se desenvolvem no plano coletivo, como afirma Nunes (2013); Nunes e Viotto Filho (2016).

Enfim, diante dos resultados observados, podemos afirmar, que a escola precisa mudar e avançar na direção da superação de proposições tradicionalistas e conservadoras de ensino e avaliação dos alunos, tendo em vista não submetê-los a um processo classificatório e, muitas vezes, excludente, que é identificado nas propostas de ensino e avaliações padronizadas e de caráter positivista tão presentes na escola.

Temos defendido, ao lado de Viotto Filho (2009) que os professores, se imbuídos de uma teoria crítica, poderão desenvolver práticas transformadoras e, desta forma, avançar no processo de construção da escola na direção de uma escola-comunidade. Isso, pela via da organização coletiva em defesa da escola como espaço essencial de humanização.

Por fim, é importante salientar que um trabalho de pesquisa-intervenção, como o que realizamos, ainda que de iniciação à ciência e às primeiras aproximações acerca da importância das atividades ludo-pedagógicas no processo de ensino e avaliação de crianças, torna-se fator 
essencial para efetivarmos as transformações tão necessárias, tanto na vida dos sujeitos, como na escola como um todo, tendo em vista o desenvolvimento multilateral dos estudantes na escola.

\section{CONSIDERAÇÕES FINAIS}

A temática que nos ocupou ao desenvolvermos essa pesquisa foi a necessidade e o desafio no processo de construção e desenvolvimento de novas possibilidades de ensino e avaliação de crianças em idade escolar inicial do Ensino Fundamental, no sentido de criarmos, a partir da teoria histórico-cultural reflexões e ações de natureza ludo-pedagógica, condições diferenciadas de humanização no interior da escola.

Salientamos ainda que o trabalho do professor precisa ser reconhecido como essencial na transformação do humano na escola, pois é o sujeito mediador dos processos de aprendizagem e desenvolvimento dos estudantes, assim como o sujeito responsável pela avaliação desse processo e, portanto, precisa estar devidamente preparado para a realização dessa tarefa, sendo que programas de formação continuada em serviços tornam-se imprescindíveis na escola.

Por fim queremos salientar a importância de participação nesse processo de pesquisa, sobretudo pela sua natureza de iniciação científica e evidenciar que o tema abordado apresenta desafios, fato que o torna ainda mais instigante e aberto à inovações e pesquisas futuras, vez que, somente pela construção de conhecimentos científicos, oriundos das relações objetivas presentes na escola ou seja, próprias do chão da escola, é que será possível afirmarmos a objetividade desses conhecimentos, os quais, quando socializados, contribuirão para a transformação da escola e, simultaneamente, para a transformação dos sujeitos da escola, os quais, ao lados de outros sujeitos, poderão, coletiva e conscientemente, construir as transformações sociais.

\section{REFERÊNCIAS}

DUARTE, N. A Individualidade Para-si - contribuições a uma teoria histórico-social da formação do indivíduo. Campinas: Autores Associados, 1993.

ELKONIN, D. Psicologia do Jogo. São Paulo: Martins Fontes, 1998.

LEONTIEV, A.N. O Desenvolvimento do psiquismo. Lisboa: Horizonte, 1978.

LIBÂNEO, J.C. Didática. São Paulo: Cortez, 1994.

MOYSES, M.A.; COLLARES, C. et al. Inteligência abstraída, crianças silenciadas: as avaliações de inteligência - retomando o tema. In: Viotto Filho, I.A.T \& Ponce, R.F. - Psicologia e educação: perspectivas críticas para a ação psicopedagógica. Birigui: Boreal, 2012.

NUNES, R. L. Atividade do jogo e desenvolvimento infantil. (Dissertação de Mestrado - Programa de Pós-graduação em Educação) - Presidente Prudente: UNESP, 2013.

VIGOTSKI, L.S. Obras Escolhidas - tomo III. Madri: Visor, 1995.

VIGOTSKI, L.S. A construção do pensamento e da linguagem. São Paulo, ed. Martins Fontes. 2001. VIGOTSKY, L.S. La imaginación y el arte em la infancia. Madrid: Akal, 2009.

VIOTTO FILHO, I. A. Teoria Histórico-Cultural e suas implicações na atuação do professor de educação física. Revista Motriz, Rio Claro, v.15 n.3 p. 687-695, jul. /set. 2009. Disponível em: http://www.periodicos.rc.biblioteca.unesp.br/index.php/motriz/article/view/2865/2537 Acessado em: 15/07/2016. 
VIOTTO FILHO, I.A.T.; A Escola-comunidade: teorias crítico-transformadoras e ações críticotransformadoras no interior da escola. In: I Congresso Internacional sobre a teoria históricocultural, 2012, Marilia. Teoria histórico-cultural em foco: perspectivas (inter) nacionais. Marilia: Oficina Universitária, 2012. v. 1. p. 10-20.

VIOTTO FILHO, I.A.T; NUNES, R.L. Jogos de papéis sociais e desenvolvimento infantil: atuando numa perspectiva humanizadora. Revista Luminária. União da Vitória/Parana, 2013. 